\title{
TRADUZINDO CULTURA VS. TRADUÇÃO CULTURAL ${ }^{1}$
}

\author{
Harish Trivedi ${ }^{1}$ \\ -University of Dehli, India \\ Tradução de Vicente Santos Mendes ${ }^{2}$ \\ ${ }^{2}$ Universidade Federal do Sul da Bahia, Itabuna, Bahia, Brasil
}

\begin{abstract}
Resumo: Tradução do Ensaio publicado “Translating Culture vs Cultural Translation" de Harish Trivedi no livro Translation-Refletctions, refractions, transformations publicado em 2007, no livro que corresponde ao número 71 da série Benjamins Translation Library.
\end{abstract}

Palavras Chave: Tradução; Cultura

\section{TRANSLATING CULTURE VS. CULTURAL TRANSLATION}

\begin{abstract}
Translation of Harish Trivedi's “Translating Culture vs Cultural Translation" Essay published in the book Translation - Refletctions, refractions, transformations published in 2007 in the book number 71 of the Benjamins Translation Library series.
\end{abstract}

Keywords: Translation; Culture

Existe um amplo consenso sobre o caso de que a tradução e os estudos da tradução nunca estiveram tão em alta. Nas últimas

${ }^{1}$ Ensaio publicado em 2007, no livro que corresponde ao número 71 da série Benjamins Translation Library<https://benjamins.com/catalog/btl.71.27tri $>$. A presente tradução foi autorizada para ser publicada em português pela Editora John Benjamins e pelo autor Harish Trivedi, aos quais agradeço imensamente. Referencia completa do ensaio original: Trivedi, Harish. Translating culture vs. cultural translation. In: ST. Pierre, Paul; Kar, Prafula C. (Eds.) Translation -Reflections, refractions, transformations. Benjamins Translation Library 71, p.277-87, 2007. 
duas ou três décadas, a tradução se tornou uma atividade mais prolífica, mais visível e mais respeitável que talvez nunca antes. E ao lado da tradução em si mesma, um novo campo de estudo acadêmico passou a existir, inicialmente chamado Tradutologia (mas não por muito tempo, graças a Deus!) e agora Estudos da Tradução, e ele tem acumulado impulso acadêmico notável. A tradução, obviamente, sempre existiu, há quase tanto tempo quanto a própria literatura existe. Mas as razões históricas para o boom atual são remontáveis provavelmente a três momentos distintos ao largo do escopo do século XX.

O primeiro deles foi o movimento concertado de traduzir ficção russa para o inglês que começou na década de 1890 e se estendeu até a de 1930, que revelou aos leitores em inglês um corpo de trabalho imaginativo de uma área fora da Europa Ocidental que era tão novo e excitante a ponto de chocar e de fato induzir um estado daquilo que foi chamado de "Febre Russa", com escritores tão diversos quanto Virginia Woolf e D. H. Lawrence não só entusiasmando-se com os recém-descobertos mestres da ficção russa do século XIX, mas de fato ajudando a traduzi-los em colaboração com o emigrado russo S. S. Koteliansky. Os outros dois momentos pertencem ao outro fim do século XX, ocorrendo como o fizeram nos anos 1970 e 1980 quando dois outros corpos de literatura de até então partes desconsideradas do mundo foram traduzidas para o inglês e causaram uma comparável sensação: da América Latina, e de países da Europa do Leste sediados atrás da Cortina de Ferro.

Diferentemente do que com a literatura russa, essas duas últimas literaturas, quando tornadas disponíveis em tradução, ajudaram a transformar globalmente as nossas próprias expectativas do como a literatura se parecesse ou devesse se parecer. Se me permitem uma digressão por um momento para ficar em casa, talvez a primeira vez em que leitores em inglês e outras línguas europeias ficaram semelhantemente chocados e maravilhados pela descoberta de uma literatura estrangeira foi nas duas últimas décadas do século XVIII quando Charles Wilkins, Sir William Jones e outros orientalistas começaram a traduzir do sânscrito, e causaram na Europa o que 
Raymond Schwab chamou de A Renascença Oriental, e que J. J. Clark chamou de $O$ Iluminismo Oriental. Mas aqueles eram outros tempos, e ao que aquela descoberta através da literatura levou não foi nenhum interesse maior em tradução, mas sim à fundação da disciplina de filologia comparada, e é claro, se formos acreditar em Edward Said, à colonização mais profunda e mais efetiva.

Como tanto a filologia comparada quanto o colonialismo já são áreas do empreendimento humano que podem ser consideradas como exauridas, os três mais novos lampejos da revelação tradutória deram origem, ao contrário, a um impulso louvável de se olhar mais de perto para o processo e o efeito da tradução em si mesma. Embora os próprios tradutores e alguns raros críticos literários também tivessem por um longo tempo refletido sobre a prática da tradução, tal atividade foi, como nós dizemos agora, teorizada em um campo autônomo de perquirição acadêmica somente há cerca de duas décadas, no ano ou em volta do ano de $1980 . \mathrm{Na}$ Inglaterra e em muitas outras partes do mundo anglófono, o nascimento dos Estudos da Tradução foi assinalado, na medida em que tal consolidação gradual é assinalada por algum evento singular, pela publicação do livro sob o título mesmo de Estudos da Tradução, por Susan Bassnett-McGuire (hoje Susan Bassnett), em 1980. Esse curto manual introdutório teve circulação e influência foras do comum, sendo reimpresso em uma segunda edição em 1991 e em uma terceira edição atualizada em 2002.

Mas um novo campo de estudos é visto nos nossos dias como tendo se tornado bem e verdadeiramente estabelecido quando não só monografias, mas também Livros Textos (ou antologias de materiais primários e críticos) e Enciclopédias do assunto começam a sair, e isso vem acontecendo continuamente em Estudos da Tradução nos últimos anos: por exemplo a Enciclopédia Routledge de Estudos da Tradução, editada por Mona Baker (1998), a Enciclopédia de Tradução Literária para o Inglês editada por Olive Classe (2000), o Guia Oxford para Literatura em Tradução Inglesa editado por Peter France (2000), e o "História da Tradução Literária para o Inglês", em cinco volumes, projetado pela Editora da Universidade 
de Oxford, assim como uma Enciclopédia em 7 volumes atualmente em andamento há alguns anos na Alemanha. A estas obras podese adicionar antologias de cunho teórico e crítico tais como Teorias da Tradução: Uma Antologia de Ensaios de Dryden a Derrida editada por Reiner Schulte e John Biguenet (1992), o Livro-Texto de Estudos da Tradução editado por Lawrence Venuti (2000), A Teoria da Tradução Ocidental: de Heródoto a Nietsche por Douglas Robinson (2001), e avaliações críticas de tais materiais tais como Teorias da Tradução Contemporânea por Edwin Gentzler (1993, edição atualizada 2001), para não mencionar um Dicionário de Estudos da Tradução por Mark Shuttleworth e Moira Cowie (1997). Revistas novas exclusivamente dedicadas ao assunto tais como The Translator foram fundadas, editoras grandes e pequenas tais como Routledge e Multilingual Matters lançaram suas séries de Estudos da Tradução, e toda uma nova editora exclusivamente dedicada ao assunto, St. Jerome, não tem ido tão mal das pernas.

A minha citação assídua dessa bibliografia seleta (como ela é geralmente relegada ao fim de um artigo) tem a intenção de mostrar não só o novo emaranhado de riquezas disponível no campo, mas também uma tendência de empurrar o âmbito da disciplina tão ampla e retrospectivamente ao passado quanto possível (a Dryden e a Heródoto, por exemplo), bem como a de lhe conferir uma linhagem acadêmica mais respeitável. Tudo isso é rememorativo das maneiras como os Estudos Pós-Coloniais emergiram enquanto uma área de estudos alguns anos somente antes dos Estudos da Tradução e, de fato, a semelhança aqui não é só incidental, mas interativa, pois pelo menos quatro estudos foram publicados nos anos recentes fazendo uma conexão explícita entre essas duas recém-florescentes áreas: $\mathrm{Si}$ ting Translation: History, Poststructuralism and the Colonial Context (1992) por Tejaswini Niranjana, The Poetics of Imperialism: Translation and Colonization from The Tempest to Tarzan (1997) por Eric Cheyfitz, Translation and Empire: Postcololial Theories Explained (1997) por Douglas Robinson, e Postcolonial Translation: Theory and Practice (1999) uma coletânea de ensaios editada por Susan Bassnett e Harish Trivedi. De um modo geral, a recentemente

Cad. Trad., Florianópolis, v. 39, no 3, p. 578-594, set-dez, 2019. 
adquirida preeminência de traduções e tradutores está mesmo refletida, premeditadamente ou não, no título de dois livros recentes: The Translator's Turn (por Douglas Robinson, 1991), que agora parece ser [evidente], e The Translator's Invisibility (por Lawrence Venuti, 1995), que agora parece ter sido substituída por uma visibilidade colocada em primeiro plano como que destacada por refletores.

Antes desses novos desenvolvimentos acontecerem, qualquer estudo de tradução era classificado sob uma dessas duas matérias ou disciplinas: Linguística e Literatura Comparada. Tradicionalmente, a tradução era vista como um segmento ou uma subárea da Linguística, a partir da premissa básica de que a tradução era uma transação entre duas línguas. O livro de J. C. Catford A Linguistic Theory of Translation: An Essay in Applied Linguistics (1965) foi talvez o último grande trabalho escrito a partir dessa assunção, em que ele definiu tradução como compreendendo uma "substituição de significados na LA (i.e. língua alvo) por significados na LF (i.e. língua fonte) citado em (Bassnett 2000, 15, tradução minha).

Mas logo depois disso, começou a ser notado que textos literários eram constituídos não primariamente de língua, mas na verdade de cultura, a língua sendo na verdade um veículo da cultura. Em discussões tradicionais, os problemas da tradução, i.e., os itens que se provavam particularmente intratáveis em tradução, eram frequentemente descritos como sendo "específicos de uma cultura" - por exemplo, kurta, dothi, roti, loochi, dharma, karma, ou maya todos itens peculiarmente indianos, e na verdade não como [os conceitos] camisa, calças, pão, religião, ações/obras tanto passadas quanto presentes, ou ilusão ocidentais. Mas então aumentou-se a percepção de que tais itens particulares não eram somente "específicos de uma cultura" mas de fato toda a língua era específica de uma cultura a qual ela pertencia ou da qual se originava, de um modo ou de outro. A hipótese Sapir-Whorf, no sentido de que uma 
língua definia e delimitava a visão de mundo particular de seus falantes, de forma que o que eles não podiam dizer na sua língua era aquilo que não podiam nem conceber, parecia apoiar a visão de que a especificidade de uma cultura era coextensiva com a especificidade de sua língua. A valorização crescente da diversidade e da pluralidade em assuntos culturais também corroborou essa nova compreensão de língua e cultura de uma forma que ideias e ideais anteriores de universalismo não tinham feito.

Assim, numa quebra de paradigma, a tradução de um texto literário tornou-se uma transação não entre duas línguas, ou um ato que soasse algo mecânico de "substituição" linguística, como Catford propusera, mas na verdade uma negociação mais complexa entre duas culturas. A unidade de tradução não era mais uma palavra ou uma sentença ou um parágrafo, ou uma página ou mesmo um texto, mas de fato toda a língua e cultura em que aquele texto estava constituído. Essa nova consciência foi acertadamente descrita como "A Virada Cultural nos Estudos da Tradução" no título de um capítulo escrito conjuntamente por Susan Bassnett e Andre Lefevere no seu livro Translation, History and Culture (1990). Foi precisamente a formulação e o reconhecimento dessa virada cultural nos Estudos da Tradução que serviu para estender e revitalizar a disciplina e liberá-la das relativamente mecânicas ferramentas de análise disponíveis na Linguística.

Aconteceu que foi aproximadamente nessa mesma época que os Estudos da Tradução alcançaram uma libertação semelhante da subserviência a uma outra disciplina da qual tinham há muito sido considerados subsidiários e meramente uma parte instrumental, a Literatura Comparada. Mas isso teve tanto a ver com o declínio da Literatura Comparada em si mesmo, especialmente nos Estados Unidos, onde o impulso e a visão revigorantes de emigrantes europeus multilíngues de antes e durante a $2^{\mathrm{a}}$ Guerra Mundial, como, por exemplo, Rene Wellek, tinha se esvaído, quanto com a ascensão dos Estudos da Tradução. Foi Susan Bassnett de novo, que tinha por muitos anos liderado o único departamento pleno de Literatura Comparada no Reino Unido, na Universidade de Warwick, que em 
seu livro intitulado Comparative Literature (1993) declarou "Hoje, a literatura comparada num certo sentido está morta" e "A literatura comparada enquanto disciplina está ultrapassada” (p. 47, 161), e prossegue explicando que enquanto o surgimento dos Estudos PósColoniais tinha diminuído o efeito de seus interesses tematológicos, o surgimento dos Estudos da Tradução tinha deixado a literatura comparada desprovida de muito de suas preocupações metodológicas. Cada vez mais hoje, estudos comparativos de literatura transversais a línguas têm se tornado objeto de interesse de Estudos da Tradução; é o rabo tradutório agora que abana o cão comparativo.

Através dos anos 90, paralelamente ao surgimento dos Estudos da Tradução, vimos também interessantemente o surgimento de um campo mais amplo e mais influente de estudos, os Estudos Culturais, sem, entretanto, nenhuma sobreposição ou interação perceptíveis entre os dois. Essa falta de convergência ou imbricação foi de novo notada por Bassnett e Lefevere no seu próximo livro, Constructing Cultures (1998), no qual eles agora tinham um capítulo final intitulado "A Virada da Tradução nos Estudos Culturais." Eles observaram que essas "interdisciplinas", como eles as chamaram, tinham se movimentado para além das suas "origens eurocêntricas" para entrar "numa nova fase internacionalista", e eles identificaram uma agenda comum de quatro pontos que os Estudos da Tradução e os Estudos Culturais poderiam abordar juntos, incluindo uma investigação de "como diferentes culturas constroem suas imagens de escritores e textos", um rastreamento de "as maneiras pelas quais os textos se tornam capital cultural através de fronteiras culturais," e uma exploração das políticas de tradução (Bassnett e Lefevere, 138). Finalmente, eles defenderam um "agrupamento de recursos" e reforçaram de novo a convergência do método e do teor disciplinares entre os Estudos da Tradução e os Estudos Culturais:

... nessas interdisciplinas multifacetadas, o isolamento é contra-producente... O estudo da tradução, como o estudo da cultura, precisa de uma pluralidade de vozes. E semelhantemente, o estudo da cultura sempre envolve o 
exame dos processos de codificação e decodificação que compreendem a tradução. (Bassnett e Lefevere, 138-39, tradução minha).

Entretanto, essa defesa por unir forças aparentemente encontrou ouvidos moucos. A claramente maior e certamente mais robusta teoricamente jamanta dos Estudos Culturais continua a roncar estrada afora negligente da oferta feita pelos Estudos da Tradução de serem colocados a bordo. Uma possível razão pode ser que a despeito de toda a convergência de base e de direção apontada por Bassnett e Lefevere, uma diferença crucial entre as duas interdisciplinas é que os Estudos Culturais, mesmo quando se debruçam sobre cultura popular ou subalterna, quase sempre operam somente em uma língua, o inglês, e frequentemente naquela alta e abstrusa variante sua chamada Teoria, enquanto que os Estudos da Tradução, embora possam de quando em quando ser teóricos, precisam sujar suas mãos com pelo menos duas línguas, uma das quais somente pode ser o inglês. De qualquer modo, enquanto a Virada Cultural nos Estudos da Tradução tinha se provado ser um ato de redefinição transformadora, a Virada da Tradução nos Estudos Culturais ainda permanece um desiderato inalcançado, uma consumação ainda somente desejada.

\section{II}

Enquanto isso, em vez da virada cultural nos estudos da Tradução, temos em nossas mãos uma besta de nome semelhante, mas muito diferente em pelagem e fibra - algo chamado Tradução Cultural. Essa é uma colocação nova e em sua nova conotação específica não é para ser confundida com um uso anterior esporádico do termo numa acepção fora de moda de tradução orientada para a cultura alvo, que pode ser chamada uma tradução orientada para o leitor, ou "domesticadora". Na verdade, o termo Tradução Cultural, no seu significado novo e corrente, não encontra qualquer ver- 
bete ou mesmo menção em nenhuma das enciclopédias e antologias recentes de tradução listadas acima.

Pareceria então ser o caso que, enquanto desejando que os praticantes dos Estudos Culturais venham dar as mãos a eles, aqueles engajados nos Estudos da Tradução nem mesmo perceberam que algo chamado Tradução Cultural já passou a existir, especialmente no domínio do discurso pós-colonial e pós-modernista, e representa algo que não poderia estar mais distante do desejo de seus corações. Pois, se há uma coisa que a Tradução Cultural não é, é a tradução da cultura. Na verdade, ela significa, como prosseguiremos argumentando, a própria extinção e apagamento da tradução como nós sempre a conhecemos e praticamos.

A mais abrangente, sofisticada e influente formulação do conceito de Tradução Cultural ocorre no trabalho do provavelmente mais proeminente teórico pós-colonial, pós-modernista dos nossos tempos, Homi Bhabha, no último capítulo (exceto "a Conclusão") do seu livro The Location of Culture (1994), intitulado "Como a novidade entra no mundo: Espaço pós-moderno, tempos pós-coloniais e os experimentos da Tradução Cultural., tradução minha" Na discussão de Bhabha, o texto literário tratado como o exemplo preeminente de tradução cultural é o romance Satanic Verses, de Salmon Rushdie, um romance escrito originalmente em inglês e lido nessa língua por Bhabha. Uma pista para o novo sentido no qual o termo tradução está sendo usado aqui é sugerida pela observação feita pelo próprio Rushdie (que Bhabha incidentemente não cita) na qual ele disse sobre si mesmo e outros escritores pós-coloniais diaspóricos: “nós somos homens transladados", (Rushdie, 16 tradução minha). Rushdie estava explorando aqui a etimologia da palavra "translation", que significa carregar ou conduzir através, e o que ele quis dizer, portanto, era que porque ele tinha nascido na travessia, presumivelmente [feita] por um avião, da Índia e Paquistão para o Reino Unido, ele era, portanto, um homem transladado. Ele deixou de nos dizer se, antes de se tornar um homem traduzido, ele era também em algum momento um homem original. 
Mas uma segunda e sobrepujante acepção na qual Rushdie também reivindicou ser um homem transladado/traduzido é precisamente a que é exposta por Homi Bhabha em seu ensaio, fazendo referencia específica a The Satanic Verses. Bhabha começa com uma epígrafe do ensaio clássico de Walter Benjamin sobre tradução: "A tradução passa através de contínuos de transformação, não [através] de ideias abstratas de identidade e similaridade'", tradução minha, citado em (Bhabha, 212). Mais tarde, numa passagem chave, Bhabha traz a desconstrução de Derrida do conceito de Benjamin de tradução como uma vida-após ou sobrevivência, para usá-la num contexto totalmente novo não intencionado nem por Benjamin nem por Derrida, i.e., o contexto da migração, do hibridismo Rushdiana/o. Para citar Bhabha:

Se hibridismo é heresia, então blasfemar é um sonho.... é o sonho da tradução enquanto 'sobrevivência', como Derrida traduziu o 'tempo' do conceito de Benjamin da vidaapós da tradução, como sur-vivre, o ato de viver nas linhas de fronteira. Rushdie traduz isso no sonho do migrante de sobrevivência; um interstício iniciático; uma condição empoderadora do hibridismo. (Bhabha 226-27) tradução minha.

Um pouco depois Bhabha diz: "A Tradução é a natureza performativa da comunicação cultural” tradução minha (Bhabha, 228), e ele continua, numa nova equação figurativa, a falar da inassimibilidade cultural residual do migrante como uma instância do que Benjamin chamou 'intradutibilidade'."

Aqui, como na verdade em inúmeros outros lugares, pode-se ficar com a sensação de que se ainda está tentando agarrar a sombra de Bhabha, enquanto já vivendo nela. $\mathrm{O}$ que, contudo, fica claro e indiscutível nas formulações de Bhabha do que ele chama tradução cultural é, primeiro, que ele por esse termo não quer dizer, em absoluto, tradução literária envolvendo dois textos de duas línguas e culturas diferentes. E, segundo, que o que ele quer dizer por tradução, 
é, em vez disso, o processo e a condição da migração humana. Para evocar uma frase, tipo mantra, irresistivelmente aliterativa e encantadora que Bhabha usa alhures mais de uma vez, o que ele está falando é da "translational transnational" "a tradutória transnacional" tradução minha (Bhabha, 173), i.e., a condição do multiculturalismo ocidental causado pela migração do Terceiro Mundo.

Desde que Bhabha primeiramente a articulou, a ideia distintamente pós-moderna de tradução cultural nessa acepção não-textual não-linguística encontrou eco em muita escrita contemporânea, tanto crítica quanto criativa. Para citar alguns poucos exemplos, o primeiro dos quais é talvez uma proto-ilustração ou um análogo de um trabalho que foi escrito antes do ensaio de Bhabha ser publicacdo, Tejaswini Niranjana, no livro dela Siting Translation, usa o termo "tradução" grosso modo para denotar o jogo de forças colonial entre os dominadores ingleses e os sujeitos indianos, e ela mesma estando consciente do fato de que isso não é o que o termo tradução normalmente significa, se vale anteriormente no seu trabalho do artifício desconstrutivo Derrideano de defender que usou o termo tradução "sob apagamento" (Niranjana 48, n.4) para se adequar ao contexto e propósito que ela própria escolheu.

Quanto à escrita criativa, Hanish Lureishi parece representar em sua carreira uma fase da tradução cultural até mais aguda e avançada que aquela exemplificada por Rushdie. Diferentemente de Rushdie, Kureishi tinha um progenitor inglês, era nascido na Inglaterra e cresceu no "país natal" de Kent, se pensando como bem completamente britânico, em vez de indiano/paquistanês ou mesmo híbrido. "Eu fui criado realmente como uma criança inglesa" ele afirmou. "[...] Eu não fui influenciado pela cultura asiática de jeito nenhum" citado em (Ranasinha, 6). Como ele colocou sem rodeios em uma outra entrevista "Eu não sou um escritor paquistanês ou indiano. Eu sou um escritor britânico" citado em (Ranasinha, 6). É fato que o trabalho de Kureishi, diferentemente do de Rushdie, não contém referência alguma à cultura sub-continental popular tais como filmes e músicas de filmes hindus. Em vez disso, Kureishi foi co-editor do The Faber Book of Pop (1995) querendo dizer claro popular no 
sentido britânico e americano. Quase todos os escritos de Kureishi têm como cenário Londres ou os subúrbios, e um deles, intitulado Sleep with Me (1999) só tem personagens britânicos brancos.

A única dificuldade com essa britanicidade demonstrável de Kureishi é que no mundo literário e cultural de Londres dos 70, quando Kureishi estava começando a despontar como escritor, ele era, todavia, classificado por editores contratantes para teatro e televisão dentro do papel de um tradutor cultural asiático. Como ele relata, "eles exigiam historias sobre as novas comunidades britânicas [de imigrantes], por tradutores culturais, como se dizia, para interpretar um lado para o outro" e embora Kureishi soubesse que como um não-migrante, verdadeiramente nascido britânico ele não era nem por criação nem por sensibilidade "o tipo de escritor mais bem qualificado para esse tipo de trabalho", ele fazia assim mesmo o serviço porque "eu simplesmente sabia que eu estava sendo pago pra escrever" tradução minha citado em (Ranasinha, 12). Nessa versão, a tradução cultural não é tanto a necessidade do migrante, como Bhabha defende, mas antes um requerimento da sociedade e da cultura para as quais o migrante viajou; é uma necessidade e uma exigência ocidental hegemônica.

Para um exemplo ainda mais eficaz e auto-induzido de tradutor cultural, podemos olhar para Jhumpa Lahiri, cujo primeiro livro de ficção, Interpreter of Maladies: Stories of Bengal, Boston and Beyond (1999) a fez a primeira escritora nascida na Índia a ganhar o Prêmio Pulitzer para ficção. Nascida de pais bengaleses em Londres, ela cresceu nos Estados Unidos e se tornou uma cidadã americana aos 18 anos. Ela mesma admite não ser realmente uma bilíngue, embora gostasse de pensar que o fosse. E ela escreveu ficção não só sobre indianos nos Estados Unidos, mas também algumas histórias sobre indianos ainda vivendo na Índia. Em resposta à crítica de que o seu conhecimento da Índia como refletido nessas histórias é demonstravelmente errôneo e defeituoso, ela disse "Eu sou a primeira pessoa a admitir que o meu conhecimento da Índia é limitado, do mesmo modo que todas as traduções são" tradução minha (Lahiri, 118). Esse tropo gratuito é sustentado e mais enfaticamente destaca- 
do quando ela prossegue dizendo que a sua representação da Índia é de fato a sua "tradução da Índia" tradução minha (Lahiri, 118). Fica logo claro que não só Lahiri enquanto autora é uma tradutora, mas também o são as personagens fictícias que ela traduz em existência: "Quase todas as minhas personagens são tradutoras, à medida que elas precisam fazer sentido do estrangeiro para sobreviver" tradução minha (Lahiri, 120). Isso ecoa, provavelmente inadvertidamente, o sur-vivre de Benjamin-Derrida, no sentido adotado por Bhabha, simplesmente como a asserção de Lahiri de que "a tradução não é só um ato linguístico finito, mas um ato cultural em andamento" tradução minha (Lahiri, 120) reitera a premissa central de Bhabha. E na conclusão desse ensaio, que Lahiri claramente quer dizer que serve como seu manifesto e apologia, ela declara:

E se eu escrevo como uma americana ou uma indiana, sobre coisas americanas ou indianas ou o que quer que seja, uma coisa permanece constante: Eu traduzo, logo eu existo (Lahiri, 120) tradução minha.

E isso de uma escritora que, como Kureishi, nunca traduziu uma palavra, e que admite que quando um de seus contos foi publicado em tradução para bengalês, que é a língua nativa de seus pais (mesmo que não fosse exatamente a dela mesma) e que por isso foi a (outra?) língua da sua infância, ela não conseguiu entender a versão traduzida - ou, como ela própria colocou, parecendo transferir a responsabilidade de si mesma para a tradução "se mostrou inacessível para mim” (Lahiri, 120) tradução minha.

Se isso é tradução cultural, talvez devamos nos preocupar com o próprio significado da palavra "tradução". Nos questionamos sobre o porquê "tradução" deveria ser a palavra de escolha numa colocação como "tradução cultural" nessa nova acepção quando palavras sancionadas teoricamente e perfeitamente boas para esse novo fenômeno tais como migração, exilio ou diáspora já estão disponíveis e correntes. Mas devido à usurpação que se deu, pode ser 
o momento para todos os homens bons e verdadeiros, assim como as mulheres, claro, que já praticaram tradução literária, ou até já leram tradução tendo consciência de que se tratava de tradução, se unirem e registrarem uma patente da palavra "tradução", se é que já não é tarde demais para fazê-lo.

Tal abuso, ou num eufemismo teórico, tal uso catacrético, do termo tradução, está, quando acaba, espelhado e amplificado através de uma explosão semântica ou diluição em uso não-teórico, popular também. Os jornais constantemente falam em como ameaças poderiam "se traduzir" em ações ou popularidade em votos; há um livro chamado "Traduzindo Los Angeles", que aparentemente não significa nada mais do que "Descrevendo Los Angeles"; e a própria Susan Bassnett recentemente escreveu que o livro de Edwin Gentzler Contemporary Translation Theories não é só um arrazoado crítico mas "efetivamente também uma tradução pois o autor transforma todo o domínio de material teórico complexo em linguagem acessível” (Gentzler, vi, tradução minha). Mas é claro, é a mesma língua, inglês, na qual tal complexidade teórica e tal acessibilidade ambas existem. Mesmo quando essas não são instancias de "tradução cultural" na acepção defendida por Bhabha, são ainda instancias de um tipo de "tradução" que não envolve dois textos, ou nem mesmo um texto, e certamente não mais que uma língua. Esses ainda são exemplos do que Bhabha, com sua felicidade usual, chamou em um outro contexto de "tradução nãosubstantiva" (em comunicação pessoal). Poderíamos talvez dar um passo adiante e, sem qualquer tentativa de satisfazer condições de felicidade, chamar isso simplesmente de "não-tradução".

Em conclusão, poderíamos sugerir que há uma necessidade premente talvez de proteger e preservar algum pouco espaço nesse mundo pós-colonial pós-modernista, onde a novidade constantemente entra através da tradução cultural, para alguma velha e fora de moda tradução literária. Pois, se esse terreno bilíngue e bicultural for erodido mais e mais, vamos acabar mais cedo que se possa imaginar com um mundo totalmente traduzido monolíngue, monocultural, monolítico. E aí, aqueles de nós que ainda formos 
bilíngues, e que não tivermos ainda sido transladados do nosso terreno nativo para costas estrangeiras, teremos sido assim mesmo traduzidos contra nossa vontade e contra nossa índole. Além disso, a tradução em si mesma teria sido intraduzida ou destraduzida, pois teria vindo à tona sob apagamento num sentido bem menos desconstrutivo do que o de Derrida mas obviamente muito mais destrutivo. O pós-colonial teria colonizado completamente a tradução, pois a tradução no sentido em que nós a conhecemos e estimamos, e o valor que ela possuiu enquanto instrumento de descoberta e intercambio, teria deixado de existir. Em vez de nos ajudar a encontrar e experimentar novas culturas, a tradução teria sido assimilada numa única cultura global monolíngue.

Toda conversa recente de multiculturalismo se relaciona, pode ser notado, não com as muitas culturas diferentes localizadas mundo afora, mas meramente com o gerenciamento social conveniente de uma amostra pequena de migrantes de algumas dessas culturas que na verdade se deslocaram e chegaram ao Primeiro Mundo, e que agora precisam ser fundidos naquele caldeirão cultural, ou misturados dentro daquela salada, ou encaixados como uma pecinha esquisita naquele mosaico. Esses indivíduos sem importância que vagavam na cultura mundial que foram bem lavados nas suas orlas são bastante suficientes para o gosto do Primeiro Mundo. Migração, frequentemente migração da elite da classe alta como por exemplo da Índia, já forneceu ao Primeiro Mundo tanta novidade quanto ele precisa ou pode com ela lidar, e deu ao Primeiro Mundo a ilusão de que essa pequena fração do Terceiro Mundo já transformou o Primeiro Mundo no mundo todo, no único mundo que existe. Aqueles de nós ainda localizados em nosso torrão natal e na nossa própria cultura e falando nossas línguas nativas não podemos mais ser vistos ou ouvidos. Toda a fala politicamente correta de ecodiversidade e biodiversidade diz respeito a um nível menos problemático e inofensivo de espécies abaixo do humano; não há um desejo correspondente de que se possa discernir por diversidade linguística ou cultural. Fundos do mundo inteiro estão sendo despejados na preservação 
e propagação do Tigre Real de Bengala, por exemplo, que foi declarado espécie em extinção, mas nenhum suporte semelhante está disponível para as línguas indianas, que parecem estar igualmente ameaçadas pela dizimação crescente das línguas do mundo pelo inglês, a língua multinacional, global, que devora todas as outras. Me ocorre que nenhuma agencia internacional poderia se interessar por salvar o Tigre Real de Bengala se ele rugisse de fato em bengalês. Poderia haver então o pequeno problema de ter que traduzir o rugido para o inglês primeiro. De qualquer forma, a WWF está comprometida em salvar somente vida selvagem, não vida dotada de cultura.

Nesse admirável mundo novo distópico de tradução cultural, a tradução teria ironicamente sido traduzida de volta, para o seu sentido literal, etimológico, de migração humana. Em uso Cristão antigo do termo, a tradução, na verdade, no sentido de nascer através ocorreu quando uma pessoa morta era corporalmente transportada para o próximo mundo, ou, numa rara ocasião, quando o corpo dela era transferido de uma tumba para outra, como ocorreu celebremente no caso de Thomas à Beckett, que foi na verdade assassinado e inicialmente enterrado perto de uma cripta da Catedral de Canterbury, mas então, cerca de 150 anos mais tarde, quando os peregrinos deixaram de ser gatos pingados e se tornaram fluxo de massa, [foi] movido e enterrado novamente dentro da mesma Catedral na grande nova Capela Trindade. Em ambos esses sentidos, de remoção corpórea para o próximo mundo, ou para a próxima tumba, estamos falando de alguém que está verdadeiramente morto e enterrado. As muitas línguas nativas do mundo e o canal de intercambio entre elas, a tradução, podem parecer fadadas ao mesmo destino na era da tradução cultural: serem mortas e enterradas. ${ }^{2}$

\footnotetext{
${ }^{2}$ Partes e versões deste ensaio foram apresentadas nas Universidades de Iowa, Essex, Warwick e Londres, e eu sou grato às minhas audiências por muitas observações e sugestões valiosas.
}

Cad. Trad., Florianópolis, v. 39, no 3, p. 578-594, set-dez, 2019. 


\section{Referências}

Bassnett, Susan. Translation Studies. London: Routledge. (1980) 2002

Bassnett, Susan. Comparative Literature: A Critical Introduction. Oxford: Blackwell. 1993.

Bassnett, Susan; Lefevere, Andre. Constructing Cultures: Essays in Literary Translation. Clevedon: Multilingual Matters. 1998.

Bhabha, Homi. The Location of Culture. London: Routledge. 1994.

Catford, J. C. A Linguistic Theory of Translation: An Essay in Applied Linguistics. London: Oxford University Press. 1965.

Gentzler, Edwin. Contemporary Translation Theories. Clevedon: Multilingual Matters. (1993) 2001.

Lahiri, Jhumpa. "My Intimate Alien". Outlook (New Dehlhi) special annual issue on "Stree" [Woman], 2000. pp. 116-20.

Niranjana, Tejaswini. Siting Translation: History, Post-Colonialism and the Colonial Context. Berkeley: University of California Press. 1992.

Ranasinha, Ruvani. Hanif Kureishi (Writers and their Work series). London: Northcote House. 2001.

Rushdie, Salmon. Imaginary Homelands: Essays and Criticism. London: Granta Books. 1991.

Recebido em: 29/03/2019

Aceito em: 30/06/2019

Publicado em: Setembro de 2019

Vicente Santos Mendes. E-mail: vicente.mendes@ufsb.edu.br

ORCID: https://orcid.org/0000-0002-6629-0421

Cad. Trad., Florianópolis, v. 39, nº 3, p. 578-594, set-dez, 2019. 